\title{
Technical efficiency of sea bass and sea bream farming in the Mediterranean Sea by European firms: A stochastic production frontier (SPF) approach
}

\author{
José L. Fernández Sánchez, Ignacio Llorente García, and Manuel Luna \\ IDES-UC Research Group, Department of Business Administration, University of Cantabria, Avda. \\ de los Castros 56, 39005 Santander, Spain.
}

\begin{abstract}
In the last years, European producers of cultured sea bass and sea bream have had to compete strongly among them as well as with Turkish producers to be competitive. One important factor of economic competitiveness is to produce efficiently. For this reason, we have evaluated the technical efficiency of European producers of cultured sea bass and sea bream in the last decade (2008-2017) using the stochastic production frontier (SPF) approach and we have analyzed the effect of some specific-firm factors in firms' productivity. To do this analysis, we have employed a representative sample of 73 European firms producing sea bass and sea bream in the Mediterranean Sea. Data for this analysis was obtained from the ORBIS and EUMOFA databases. The majority of European firms producing cultured sea bass and sea bream in the Mediterranean Sea presented a productivity over $90 \%$, being Cypriot and Greek firms the most productive. We have also found evidence that technical efficiency of these firms is positively related to their location (better environmental conditions in the Eastern Mediterranean Sea) and size (increasing production returns related to a higher level of quality in the making decisions or in the organization of the production process).
\end{abstract}

\section{KEYWORDS}

Aquaculture; Production; Efficiency; Stochastic frontier; Sea bass

\section{JEL CLASSIFICATION}

D24, Q22

\section{ACKNOWLEDGEMENTS}

This study has been carried out with the financial support of the Commission of the European Communities' Horizon 2020 research program, Grant Agreement 7271315, MedAID (Mediterranean Aquaculture Integrated Development).

\section{ORCID}

José L. Fernández Sánchez https://orcid.org/0000-0002-1042-7572

\section{CONTACT}

Prof. José L. Fernández Sánchez, Department of Business Administration, University of Cantabria, Avda. de los Castros 56, 39005 Santander (Spain). E-mail: fernandezjl@unican.es. 


\section{AUTHOR'S BIOGRAPHIES}

José L. Fernández Sánchez is professor of business economics and researcher of the IDES research group at the University of Cantabria in Santander (Spain). He gets a PhD in Business Administration from University of Cantabria and two master's degrees in marketing (ESIC) and Economics (Queens College, CUNY). His research interests are related to firm's performance, social and environmental responsible policies, value chain analysis, as well as the economic sustainability of the seafood production and processing sectors.

Ignacio Llorente García is assistant professor of business economics and researcher of the IDES research group at the University of Cantabria in Santander (Spain). He gets a $\mathrm{PhD}$ in Business Administration and a master's degree in Business Administration (MBA) from University of Cantabria. His research interests are related to bioeconomic models, operational optimization, and value chain analysis of the seafood farming and processing industries.

Manuel Luna is a researcher of the IDES group at the University of Cantabria focused on data management and AI techniques applied to the decision-making process. He has master's degrees in Banking and Financial Markets, Strategic Planning, as well as in Data Science and Big Data. He's currently a $\mathrm{PhD}$ candidate in Business Administration. His research interests are related to the optimization of production processes and data management in the aquaculture and fishing sectors.

This is an Author's Original Manuscript of an article published by Taylor \& Francis in Aquaculture Economics \& Management on 5 November 2020, available online: http://www.tandfonline.com/ 10.1080/13657305.2020.1840660. 


\section{Technical efficiency of sea bass and sea bream farming in the Mediterranean Sea by European firms: A stochastic production frontier (SPF) approach}

\section{Introduction}

European sea bass (dicentrarchus labrax) and gilthead sea bream (sparus aurata) are economically important cultured fish species along the Mediterranean coast. Traditionally, sea bass and sea bream have been farmed extensively in the coastal lagoons and brackish ponds in northern Italy (vallicultura) and southern Spain (esteros) where fish is allowed to enter inside the lagoons to be trapped and fed naturally until it is harvested (EU, 2012), although only a few farms still use these traditional methods to grow fish. On the other hand, at the end of the 70's and the beginning of the 80's, intensive rearing methods based on complex hatchery techniques were developed and implemented in most Mediterranean countries to substitute traditional extensive farming methods. However, nowadays, a large part of the production is cultivated in floating cages in the sea.

In 2015 both species represented respectively the $9.88 \%$ and $10.83 \%$ of the total value of the European aquaculture sector (EU, 2018). The EU is one of the largest producers of sea bass and sea bream in the world (EU, 2012), being Greece the largest producer within the EU followed by Spain (see Table 1). The figures in Table 1 show that in 2017 the total European production of cultured sea bass and sea bream was around 174,038 tons equally divided for each specie (54.5\% of sea bream and $45.5 \%$ of sea bass). The main producer is Greece with 100,232 tons, which represents the $57.6 \%$ of the total European production, followed by Spain with 34,661 tons (a 19.9\% of the total production), whereas the smallest producers in Europe are Slovenia and Portugal with only 80 and 1,739 tons respectively.

Table 1 about here

In the last years, European producers of cultured sea bass and sea bream have had to compete strongly among them as well as with Turkish producers to be competitive (Globefish, 2015). One important factor of economic competitiveness is to produce efficiently. Efficiency studies on aquaculture are relatively few compared with other industries and they are focused mainly on no European countries (Alam, 2011). Moreover, the identification of the factors that determine 
aquaculture firms' productivity is also an important issue in order to propose managerial decisions in the sector. Therefore, the purpose of this work is twofold: first, we have evaluated the technical efficiency of European producers of cultured sea bass and sea bream using the stochastic production frontier approach and, second, we have analyzed the effect of some specific-firm factors such as location, production type (organic), years of experience, and size on firms' inefficiency.

\section{Technical efficiency: definition and measurement}

Most of the literature about efficiency is based on Farrell's pioneer paper (1957) who developed a conceptual model involving the contraction of inputs to an efficient frontier (Tingley, Pascoe, \& Coglan, 2005). Technical efficiency (hereinafter, TE) refers to the ability of a decision-making unit (farm or firm) to minimize input used in the production of a given bundle of outputs, or the ability to obtain maximum output from a given bundle of inputs (Farrell, 1957; Kumbhakar \& Lovell, 2000; Alam, 2011). These two definitions of TE lead to what is known as output and input-oriented efficiency measures respectively.

The measurement of TE is based upon deviations of observed output from the best production or efficient production frontier. The frontier production function defines potential output that can be produced by a firm with the given level of inputs and technology (Kumar, Birthal, \& Badruddin, 2004). If a firm's actual production point lies on the frontier, it is perfectly efficient whereas if it lies below the frontier, then it is technically inefficient, being the ratio of actual to potential production the level of efficiency. Two methodologies are commonly used to describe the efficient production frontier and, therefore, estimate efficiency values (Tingley et al., 2005): the stochastic production frontier (SPF) and the data envelopment analysis (DEA). Both approaches have been widely used to analyze productivity in the aquaculture sector for different species and countries (Iinuma, Sharma, \& Leung, 1999; Sharma, Leung, Chen, \& Peterson, 1999; Dey, Paraguas, Bimbao, \& Regaspi, 2000; Ara, Alam, Rahman, \& Jabbar, 2004; Dey, Paraguas, Srichantuk, Xinhua, Bhatta, \& Dung, 2005; Bozoglu, Ceyhan, Cinemre, Demiryurek, \& Lilic, 2006; Cinemre, Ceyhan, Bozoglu, Demiryurek, \& Kilic, 2006; Kaliba \& Engle, 2006; Alam \& Murshed-e-Jahan, 2008; Alam, 2011; Islam, Tai, \& Kusairi, 2016; Ngoc, Gaitán-Cremaschi, Meuwissen, Le, Bosma, Verreth, \& Lansink, 2018).

Any of these approaches has its advantages and disadvantages. The SPF approach is a parametric method that accounts for production uncertainty (stochastic noise), allows simultaneous estimation of individual technical efficiency of firms as well as determinants of technical efficiency, and permits statistical tests of hypotheses pertaining to production structure and the degree of inefficiency (Battese \& Coelli, 1995). On the other hand, the DEA approach does not assume a parametric form for the production technology and does not make assumptions about the error term, assuming that an agent's 
inability to produce the maximal output, given their input mix, is due to agent-specific technical inefficiency (Aigner, Lovell, \& Schmidt, 1977; Meeusen \& van den Broeck, 1977). In this case efficiency frontier is constructed with the help of the linear programming technique developed by Charnes, Cooper, and Rhodes (1978) that puts more efficient firms in the frontier ray being the distance between this ray and the location of other firms which are not in this ray the efficiency measure. DEA is, consequently, a more general and flexible model than its parametric counterpart, although its results are very sensitive to outliers and sampling variation (Cesaro, Marongiu, Arfini, Donati, \& Capelli, 2009). For all these reasons, the application of the SPF approach has been used for the assessment of TE in a wide range of industries (Tingley et al., 2005) whereby we have decided to employ this approach in our research.

According to Battese and Coelli $(1992,1995)$, a general SPF model for panel data can be given by:

$$
\operatorname{Ln} Y_{i t}=\operatorname{Ln}\left(\mathbf{x}_{i t}, \boldsymbol{\beta}\right)+v_{i t}-u_{i t}
$$

were $Y_{i t}$ denotes the production of the $i$-th firm at the $t$-th time period; $\mathbf{x}_{\text {it }}$ is a vector of input quantities and $\boldsymbol{\beta}$ is a vector of unknown parameters to be estimated. Besides, $u_{i t}$ is a time-varying panel-level effect to estimate the technical inefficiency of the firm $i$ at year $t$ (where $u_{i t} \geq 0$ ) and $v_{i t}$ is assumed to be an independent and identically distributed $N\left(0, \sigma_{v}^{2}\right)$ random error independent of the $u_{i t}$ and the covariates in the model. When $u_{i, t}=0$, the $i$-th firm lies on the stochastic frontier and, hence, can be considered technically efficient at time $t$. If $u_{i, t}>0$, the production lies below the frontier and, hence, the $i$-th firm is inefficient. Then, technical efficiency of the $i$-th firm at the $t$-th time period $\left(T E_{i t}\right)$ can be expressed as the ratio of actual (observed) output relative to the potential (maximum feasible) output (Lachaal, Chebil, \& Dhehibi, 2004):

$$
T E_{i t}=\frac{L n Y_{i t}}{E\left(L n Y_{i t} / u_{i t}=0, x_{i t}\right)}=e^{\left(-u_{i t}\right)}
$$

so that this measure takes values between 0 and 1 with smaller ratios reflecting greater inefficiency (inverse relationship).

The inefficiency term can follow different specifications about its time behavior considering that it can be fixed or variable across the years. Thus, if we have a time-varying specification proposed by Battese and Coelli (1992), $u_{i t}$ would be:

$$
u_{i t}=u_{i} \cdot e^{-\eta\left(t-T_{i}\right)}
$$


where $T_{i}$ is the last period in the $i$-th panel, $\eta$ is the decay parameter, and $u_{i} \sim N^{+}\left(\mu, \sigma_{u}^{2}\right)$. When $\eta>0$, the degree of inefficiency decreases over time whereas when $\eta<0$, the degree of inefficiency increases over time. On the other hand, when $\eta=0$, the time-varying decay model reduces to the time-invariant model $\left(u_{i t}=u_{i}\right)$. However, all these specifications do not define the inefficiency effects in terms of specific-firm explanatory variables as the Battese and Coelli's (1993, 1995) model does, in which the inefficiency effects, $u_{i t}$, in the stochastic frontier model (1) can be specified as:

$$
u_{i t}=z_{i t} \delta+w_{i t}
$$

where $z_{i t}$ is a set of explanatory variables, $\delta$ an unknown vector of coefficients, and $w_{i t}$ a set of random variables. These random variables are defined by the truncation of the normal distribution with zero mean and variance, $\sigma^{2}$, such that the point of truncation is $-z i t \delta$ (Battese \& Coelli, 1993).

There are several potential functions for the SPF, being the logarithmic transcendental (translog) and Cobb-Douglas production functions the most common. A translog function is given by:

$$
\operatorname{Ln} Y_{i t}=\beta_{0}+\sum_{j} \beta_{j} \operatorname{Ln} X_{i t, j}+\frac{1}{2} \sum_{j} \sum_{k} \beta_{j, k} \operatorname{Ln} X_{i t, j} \operatorname{Ln} X_{i t, k}+v_{i t}-u_{i t}
$$

On the other hand, the Cobb-Douglas function is a special case of the translog production function where all $\beta_{j, k}=0$. In this case we would have the following model:

$$
\operatorname{Ln} Y_{i t}=\beta_{0}+\sum_{j} \beta_{j} \operatorname{Ln} X_{i t, j}+v_{i t}-u_{i t}
$$

Both production functions are widely used to represent the technological relationship between the amounts of two or more inputs and the amount of output that can be produced by those inputs. The main advantages of the translog over the Cobb-Douglas production function is that it permits to pass from a linear relationship between the output and the production factors to a non-linear one (Pavelescu, 2011). Besides, it does not assume any specific premises such as the perfect substitution between production factors as well as the perfect competition on the production factors' market (Klacek, Vosvrda, \& Schlosser, 2007; Pavelescu, 2011).

Of particular concern for economists and firms' managers is to know whether or not the technology exhibits increasing, decreasing, or constant returns to scale. Thus, the technology is said to exhibit increasing, decreasing, or constant returns to scale if a proportional increase in all inputs results in a 
more than, less than, or same proportional increase in output (Alam, 2011). The elasticity of production with respect to the factor $j$, which represents the percentage change in output derivable from the percentage change of factor input $j$, is equal to $\beta_{j}$ in a Cobb-Douglas production function so that it is a constant value regardless the period of time, whereas for the translog function it is defined by:

$$
\varepsilon_{j t}=\partial \operatorname{Ln} Y_{i t} / \partial \operatorname{LnX} X_{j}=\beta_{j}+\beta_{j j} \operatorname{Ln} X_{i t, j}+\sum_{j \neq k} \beta_{j k} \operatorname{Ln} X_{i t, k}
$$

In this last case, however, elasticities are no longer fixed and identical for all the individuals and periods, and they also depend on the quantities of other input factors (Helali \& Kalai, 2015).

\section{Methodology}

Data

We have used an unbalanced panel data set composed of a representative sample of 73 European firms producing cultured sea bass and sea bream in the Mediterranean Sea over the period 2008 to 2017 (this sample, which includes the most important firms in the sector, represents around the $70 \%$ of the total producers according to our own estimations). We count for this analysis with 591 observations in total since there are 139 missing values. Data was obtained from the ORBIS and EUMOFA databases and all monetary figures are presented in USD. From an econometric point of view, the use of panel data has some advantages over cross section data in the estimation of stochastic frontier models since either it makes possible to relax the strong distributional assumptions made with cross sectional data or gives estimates of technical efficiency with more desirable statistical properties (Lachaal et al., 2004).

\section{Method}

Considering that our dataset includes a rather long period of observations ( $T=10$ years), a time-varying specification of inefficiency seems to be the most plausible choice. Consequently, we adopted the Battese and Coelli's (1993, 1995) SPF model for panel data to estimate technical efficiency of European sea bass and sea bream firms. To perform the analysis, we used translog and Cobb-Douglas production functions in which the inefficiency effect $\left(u_{i t}\right)$ has a truncated normal distribution with mean $\left(Z_{i t} \delta\right)$, where $Z_{i t}$ is a set of covariates explaining the mean of inefficiency. The formulation of the empirical model employed in this research using a Cobb-Douglas SPF is specified as follows:

$$
\operatorname{Ln}\left(Y_{i t}\right)=\beta_{0}+\beta_{1} Y E A R_{t}+\beta_{2} \operatorname{Ln}\left(L A B_{i t}\right)+\beta_{3} \operatorname{Ln}\left(C A P_{i t}\right)+v_{i t}-u_{i t}
$$


where $L n$ denotes the natural logarithm; $Y_{i t}$ is the production (tons) of cultured sea bass and sea bream of the $i$-th firm at the $t$-th time period estimated dividing each firm's annual revenues between the yearly weighted average price of sea bass and sea bream in the national market of the firm; $Y E A R_{t}$ is a variable to account for a technological change and indicates the year of the observation involved (Battese \& Coelli, 1995); $L A B_{i t}$ is the labor employed by each firm (number of employees); $C A P_{i t}$ is the total capital invested by a firm measured by firms' total assets (millions of USD); $\beta_{2}$ and $\beta_{3}$ are the output elasticities of labor and capital invested respectively; $v_{i t}$ is a random error term to capture errors beyond the firm's control which is distributed independently and identically $N\left(0, \sigma_{v}^{2}\right)$; and $u_{i t}$ is the error term used to denote technical inefficiency in production process, which is presumed to be nonnegative and distributed independently of $v_{i t}$, such that $u_{i t}$ is obtained by truncation (at zero) of the normal distribution with mean, zit $\delta$, and variance, $\sigma^{2}$. The choice of variables introduced in the production frontier model has been subject to the production economic theory and data availability.

Simultaneously, the technical inefficiency values estimated with the specified SFP model were regressed using different specific-firm factors as follows (hereinafter it will be referred as the inefficiency effects model):

$$
u_{i t}=\delta_{0}+\delta_{1} Y E A R_{t}+\delta_{2} W E S T_{i}+\delta_{3} E A S T_{i}+\delta_{4} O R G_{i}+\delta_{5} A G E_{i t}+\delta_{6} S I Z E_{i t}+w_{i t}
$$

where $Y E A R_{t}$ has been defined formerly and it is included in the inefficiency effects model (9) to verify the existence of a yearly trend in firms' inefficiency; WEST $i$ and $E A S T_{i}$ are dummy variables to control firms' location, ${ }^{1}$ being $W E S T_{i}=1$ when the $i$-th firm is located in the West Mediterranean Sea (Spain and France) and 0 otherwise and $E A S T_{i}=1$ when it is located in the East Mediterranean Sea (Cyprus and Greece) and 0 otherwise; $O R G_{i}$ is a dummy variable to differentiate the organic and no-organic system of production, being $O R G_{i}=1$ when the $i$-th firm is producing organic fish and 0 otherwise since organic production can be more or less efficient in the use of inputs in the production process (Lakner \& Breustedt, 2015); $A G E_{i t}$ is the experience of the $i$-th firm at the $t$-th time period measured as year $t$ minus the firm's year of establishment since the more years of experience operating in the market could have a positive effect on firms' knowledge to employ the inputs what would increase their productivity (Misra \& Misra, 2014; Iliyasu, Mohamed, \& Terano, 2016); SIZE $i t$ is the dimension of the $i$-th firm at the $t$-th time period measured with the inverse of firm's total annual revenues (millions of USD) so that larger firms are more efficient because they would obtain increasing

\footnotetext{
${ }^{1}$ This variable can be a proxy for possible differences in general physical and environmental conditions (Tzouvlekas, Pantzios, \& Fotopoulos, 2001). For example, the average temperature of the sea, which is higher in the East Mediterranean Sea, is a recognized factor that influences positively in fish growth (Llorente \& Luna, 2013).
} 
production returns related to a higher level of quality in the making decisions or in the organization of the production process (Alvarez \& Crespi, 2003; Misra \& Misra, 2014; Rezitis \& Kalantzi, 2016). ${ }^{2}$ Consequently, the intercept of the model, $\delta$, captures the average efficiency of those firms located in the Middle Mediterranean Sea (Croatia, Italy, and Slovenia) that are not producing organic fish.

Maximum likelihood (ML) estimates of the parameters of the stochastic frontier and the inefficiency effects models were obtained simultaneously using the sfpanel command in the STATA statistical software package (version 12.0) developed by Belotti, Daidone, Ilardi, and Atella (2013). The statistical properties of these estimates are explicitly discussed in Battese and Coelli (1993).

\section{Analysis of results}

\section{Sample characteristics}

Descriptive statistics of the variables used to estimate the SPF (8) and the inefficiency effects (9) functions are presented in Table 2. The average production (output) of cultured sea bass and sea bream in our sample was 3,776 tons with a range between 2 and 58,931 tons so that we have employed a sample with a wide distribution of the dependent variable in which we have micro, small, medium, as well as large firms. Regarding factor inputs, the average of labor employed by the sampled firms is around 77 employees and the invested capital (total assets) is 34.6 million of USD. As for the variables to explain technical inefficiency, the $26 \%$ of the sample is composed of firms located in the Western Mediterranean Sea (France and Spain) and the $42 \%$ is located in the East Mediterranean Sea (Cyprus and Greece). Moreover, the $29 \%$ of firms is producing organic sea bass and sea bream. Finally, the average years of experience of these firms is almost 17 years and the average firms' size, measured by the inverse of their annual revenues (in millions of USD), is 0.78 .

Table 2 about here

\section{Estimates of the SPF}

Robust maximum-likelihood (ML) estimates of a time-variant SPF model with a truncated normal inefficiency distribution for the Cobb-Douglas and translog production functions obtained with a sample of 73 European firms producing cultured sea bass and sea bream in the Mediterranean Sea are

\footnotetext{
${ }^{2}$ We have used the inverse of income instead of income directly, or other transformations (logarithmic or power), because it has been the only option to obtain the parameter estimates of our model since the estimation method required a convergence of the different solutions (iterative process).
} 
presented in Table 3. Our results show that the two production functions are strongly significant $(p<$ 0.01 ) with a $\chi^{2}$ value in the likelihood ratio test of $1,599.92$ and 4,275.35 respectively. Next, we have tested if there is significant technical inefficiency using the null hypothesis $H_{0}: \lambda=0$, which tests whether the observed variations in efficiency are simply random or systematic. If $\lambda$ is zero, the differences in the production will be entirely related to statistical noise, while if $\lambda$ is different to zero reveals the presence of technical inefficiency. The estimate of parameter lambda was equal to $\lambda=3.7169(p<0.01)$ for the Cobb-Douglas production function and $\lambda=4.6050(p<0.01)$ for the translog function. This result indicates the presence of inefficiency in Mediterranean production of cultured sea bass and sea bream, indicating that the difference between the observed output and frontier output is not due to the statistical variability alone but also due to technical inefficiency. Therefore, a high proportion of the output variance is explained by the existing differences in the degree of technical inefficiency in these firms $(78.80 \%$ in the Cobb-Douglas production function and $82.16 \%$ in the translog form).

Moreover, according to the results presented in Table 3, in the Cobb-Douglas production function all slope coefficients have the positive expected signs and they are highly significant $(p<0.01)$. Furthermore, the sum of all slope coefficients in the Cobb-Douglas function is equal to 0.9619 so that we can reject the null hypothesis $H_{0}: \beta_{2}+\beta_{3}=1\left(\chi^{2}{ }_{1}=8.38, p<0.01\right)$, revealing that the firms we have used in our analysis are operating, on average, at decreasing returns to scale. The variable of capital $(C A P)$ has the highest elasticity $\left(\beta_{3}=0.6587\right)$, whereas labor $(L A B)$ is the variable with the lowest elasticity $\left(\beta_{2}=0.3032\right)$. In the case of the translog production function, four parameters were found to be statistically significant at the $1 \%$ significance level. In contrast, the coefficient of the trend variable $(Y E A R)$ was not significantly different to zero in any case, so that we cannot accept the hypothesis of technical change. The choice of the model that better fits to the data is done utilizing the likelihood-ratio (LR) test. ${ }^{3}$ Regarding this point, it can be inferred that the translog function is the most appropriate functional form since the null hypothesis $H_{0}: \beta_{j, k}=0$ was rejected $\left(\chi^{2}{ }_{3}=38.82, p<0.01\right)$.

Table 3 about here

\footnotetext{
${ }^{3}$ The likelihood-ratio test statistic, $\mathrm{LR}=-2\left[\operatorname{Ln}\left\{L\left(H_{0}\right)\right\}-\operatorname{Ln}\left\{L\left(H_{1}\right)\right\}\right]$ where $L\left(H_{0}\right)$ and $L\left(H_{1}\right)$ are the values of the likelihood function under the null $\left(H_{0}\right)$ and the alternative hypothesis $\left(H_{1}\right)$ respectively, has approximately a chi-square $\left(\chi^{2}\right)$ distribution with the degrees of freedom given by the number of restrictions (parameters equal to zero) imposed in the null hypothesis.
} 


\section{Determinants of $T E$}

The impact of any specific-firm factor on firms' inefficiency, estimated through the coefficients $\delta$, are presented in Table 3 as well. First of all, the estimated coefficient of the yearly trend $\left(\delta_{1}\right)$ is positive, although it is not significant in any case. In consequence, we cannot accept the existence of a declining trend in technical efficiency throughout the ten-year period.

By contrast, the results of Table 3 show that the estimated coefficients of the dummy variables included in the inefficiency effects model to control the firms' location are both negative and statistically significant, being the coefficient of the $E A S T$ variable $\left(\delta_{3}\right)$ larger than the coefficient of the WEST variable $\left(\delta_{2}\right)$. Therefore, firms located in the East Mediterranean Sea appear to be more efficient than firms located in other Mediterranean zones, being the firms located in the middle of the Mediterranean Sea the most inefficient on average. According to this finding, we can infer that some environmental factors related to the locations of firms (e.g., sea temperature) could be impacting positively on firms' productivity. A similar result to this one was also reported by Llorente and Luna (2013). Moreover, the positive sign of the coefficient associated with the firm's size $(\delta 6)$ is highly significant $(p<0.01)$ what implies that large firms are comparatively more efficient than small firms since the size variable has been measured with the inverse of firms' annual revenues.

The rest of the estimated coefficients about the firm's production type $\left(\delta_{4}\right)$ and experience $(\delta 5)$ are both negative, indicating that these factors led to decrease technical inefficiency. Thus, the results of Table 3 indicate that the production system of those firms producing organic fish has a positive impact on firms' productivity, although this effect is not statistically significant with any production function. Therefore, we have not found any empirical evidence that organic production could be more inefficient than non-organic. The same result was obtained from firms' experience. Thus, the evidence obtained shows that firms' productivity increases when firms have more years of experience, although this effect is neither statistically significant with any production function.

\section{TE values}

The annual evolution of firms' average estimates of TE values in the period 2008-2017 is showed in Figure 1. In Figure 1 we can observe that the annual TE mean presents two different patterns during the last decade with a very smooth decreasing linear trend between 2008-2014 (the TE mean decreased from 0.936 in 2008 up to 0.891 in 2014), and a small increase of it after 2014 (the TE mean grew up to 0.910 three years later). Hence, the average efficiency of European firms producing cultured sea bass and sea bream in the Mediterranean Sea has been always over the $89 \%$ throughout the ten-year period. 
Figure 1 about here

The distributions of firms' average estimates of TE values in decile range and by country are presented in Tables 4 and 5 respectively. Regarding the distribution of TE values by deciles (Table 4), we observe a concentration of these values in the superior deciles whereas there is only one firm operating below the 60 per cent of technical efficiency. On the other hand, the majority of firms presents a productivity over 0.90 (the $61.6 \%$ of the sampled firms). Therefore, we can infer that the average level of productivity of European firms producing cultured sea bass and sea bream in the Mediterranean Sea was very high throughout the 2008-2017 period with a TE mean value of 0.891 (see Table 5).

Table 4 about here

On the other hand, the analysis of TE values by country (Table 5) shows a wide variation in the average of the estimated technical efficiencies among the European countries, ranging between 0.820 of Croatia and 0.991 of Cyprus. At the same time, some countries present a wide distribution of their TE values what can be considered a wide room for improvement in their technical efficiency. Thus, TE values of Italian firms vary from 0.594 to 0.988 , with a mean value of 0.843 , as well as the TE values of Croatian and Greek firms with productivity ranges of 0.276 and 0.254 respectively. On average, Cypriot firms seem to be the most productive, with a TE mean of 0.991. These firms also present a very short variation in their technical efficiency (TE range $=0.063$ ). However, Croatian and Slovenian firms seem to be, on average, the least productive with a TE mean of 0.820 and 0.830 respectively. According to the findings presented in our analysis, the location (East Mediterranean Sea) and the larger size are two factors that are impacting positively in the productivity of Cypriot and Greek firms (they are located in the East Mediterranean Sea and have an average size of 0.10 and 0.39 respectively), whereas they are impacting negatively in the technical efficiency of Croatian and Slovenian firms (they are located in the Middle Mediterranean Sea and have an average size of 1.54 and 1.15 respectively). 


\section{Conclusions}

The purpose of this work has been twofold: first, we have evaluated the technical efficiency of European producers of cultured sea bass and sea bream in the Mediterranean Sea in the last decade, from 2008 to 2017, using the stochastic production frontier (SPF) approach and, second, we have analyzed the effect of some specific-firm factors such as location, production type (organic), years of experience, and size on firms' inefficiency. To do this analysis, we have used an unbalanced panel composed of a representative sample of 73 firms from 7 European countries (Croatia, Cyprus, France, Greece, Italy, Slovenia, and Spain) producing sea bass and sea bream in the Mediterranean Sea. Economic data for this analysis was obtained from the ORBIS and EUMOFA databases. Maximum likelihood (ML) estimates of the parameters of the stochastic frontier and the inefficiency effects model were obtained simultaneously employing the Battese and Coelli's $(1993,1995)$ SPF model for panel data.

According to the results obtained with the Cobb-Douglas production function, the firms used in our analysis were operating at decreasing returns to scale although they were operating very close to the unity. Furthermore, capital was the input factor with the highest elasticity, being labor the factor with the lowest elasticity. We have not also found empirical evidence of technical change in factors' productivity.

In the last decade (2008-2017), the majority of European firms producing cultured sea bass and sea bream in the Mediterranean Sea presented a productivity over $90 \%$ with a TE mean value of $89.1 \%$. On average, Cypriot and Greek firms seem to be the most productive with a TE mean value of $99.1 \%$ and $93.6 \%$ respectively, whereas the Croatian and Slovenian firms seem to be the least productive with a TE mean value of $82 \%$ and $83 \%$ respectively. Our findings also show a wide variation in the average of the estimated technical efficiencies among the European countries or even within some countries (e.g., Italy) what can be considered a wide room for improvement in firms' technical efficiency. Moreover, we have not observed any increasing or decreasing trend in technical efficiency throughout the analyzed period of research.

Finally, we have also found evidence that technical efficiency of those firms that are farming sea bass and sea bream in the Mediterranean Sea is positively related to their location, probably due to better physical and environmental conditions (e.g., firms located in the Eastern Mediterranean Sea presented, on average, better efficiency values), and size (increasing production returns related to a higher level of quality in the making decisions or in the organization of the production process). Thus, 
the location (East Mediterranean Sea) and larger size of Cypriot and Greek firms are two factors impacting positively on their technical efficiency, whereas the location (Middle Mediterranean Sea) and smaller size of Croatian and Slovenian firms are impacting negatively on it.

\section{References}

Aigner, D. J., Lovell, C. A. K., \& Schmidt, P. (1977). Formulation and estimation of stochastic frontier production function models. Journal of Econometrics, 6(1), 21-37.

Alam, Md. F. (2011). Measuring technical, allocative and cost efficiency of pangas (Pangasius hypophthalmus: Sauvage 1878) fish farmers of Bangladesh. Aquaculture Research, 42(10), 14871500.

Alam, Md. F., \& Murshed-e-Jahan, K. (2008). Resource allocation efficiency of the prawn-carp farmers of Bangladesh. Aquaculture Economics \& Management, 12(3), 188-206.

Alvarez, R., \& Crespi, G. A. (2003). Determinants of Technical Efficiency in Small Firms. Small Business Economics, 20(3), 233-244.

Ara, L. A., Alam, Md. F., Rahman, M. M., \& Jabbar, M. A. (2004). Yield Gaps, Production Losses and Technical Efficiency of Selected Groups of Fish Farmers in Bangladesh. Indian Journal of Agricultural Economics, 59(4), 808-818.

Battese, G. E., \& Coelli, T. J. (1992). Frontier production functions, technical efficiency and panel data: With application to paddy farmers in India. Journal of Productivity Analysis, 3(1/2), 153-169.

Battese, G. E., \& Coelli, T. J. (1993). A stochastic frontier production function incorporating a model for technical inefficiency effects. Working Paper 93/05, Department of Econometrics, University of New England, Armidale, Australia.

Battese, G. E., \& Coelli, T. J. (1995). A model for technical inefficiency effects in a stochastic frontier production function for panel data. Empirical Economics, 20(2), 325-332.

Belotti, F., Daidone, S., Ilardi, G., \& Atella, V. (2013). Stochastic frontiers using Stata. Stata Journal, 13(4), 719-758.

Bozoglu, M., Ceyhan, V., Cinemre, H. A., Demiryurek, K., \& Lilic, O. (2006). Evaluation of Different Trout Farming Systems and Some Policy Issues in the Black Sea Region, Turkey. Journal of Applied Sciences, 6(14), 2882-2888.

Cesaro, L., Marongiu, S., Arfini, F., Donati, M., \& Capelli, M. G. (2009) Methodology for Analysing Competitiveness, Efficiency, and Economy of Scale. Use and applications of DEA. FACEPA Deliverable no. D5.1.3, INEA, Italy.

Charnes, A. W., Cooper, W. W., \& Rhodes, E. (1978). Measuring the efficiency of decision-making units. European Journal of Operational Research, 2(6), 429-444. 
Cinemre, H. A., Ceyhan, V., Bozoglu, M., Demiryurek, K., \& Kilic, O. (2006). The Cost Efficiency of Trout Farms in the Black Sea Region, Turkey. Aquaculture, 251(2-4), 324-332.

Dey, M. M., Paraguas, F. J., Bimbao, G. B., \& Regaspi, P. B. (2000). Technical efficiency of tilapia growout pond operations in the Philippines. Aquaculture Economics \& Management, 4(1-2), 33-47.

Dey, M. M., Paraguas, F. J., Srichantuk, N., Xinhua, Y., Bhatta, R., \& Dung, L. T. C. (2005). Technical efficiency of freshwater pond polyculture production in selected Asian countries: Estimation and implication. Aquaculture Economics \& Management, 9(1-2), 39-63.

EU (2012). Fisheries and Aquaculture in Europe, No. 59, December. European Commission, DG for Maritime Affairs and Fisheries, Belgium.

EU (2018). Facts and figures on the common fisheries policy. Basic statistical data, 2018 Edition, Luxembourg.

Farrell, M. J. (1957). The measurement of productive efficiency. Journal of Royal Statistical Society, 120(3), 253-281.

Globefish (2015). Analysis and information on world fish trade. Market reports: European seabass and Gilthead seabream - March 2015. http://www.fao.org/in-action/globefish/market-reports/resourcedetail/fr/c/429234/

Helali, K., \& Kalai, M. (2015). Estimate of the elasticities of substitution of the CES and translog production functions in Tunisia. International Journal of Economics and Business Research, 9(3), 245-253.

Iinuma, M., Sharma, R., \& Leung, P. (1999). Technical efficiency of carp pond culture in peninsula Malaysia: An application of stochastic production frontier and technical inefficiency model. Aquaculture, 175(3-4), 199-213.

Iliyasu, A., Mohamed, Z. A., \& Terano, R. (2016). Comparative analysis of technical efficiency for different production culture systems and species of freshwater aquaculture in Peninsular Malaysia. Aquaculture Reports, 3, 51-57.

Islam, G. Md. N., Tai, S. Y., \& Kusairi, M. N. (2016). A stochastic frontier analysis of technical efficiency of fish cage culture in Peninsular Malaysia. SpringerPlus, 5(1), 127-137.

Kaliba, A. R., \& Engle, C. R. (2006). Productive efficiency of catfish farms in Chicot County, Arkansas. Aquaculture Economics \& Management, 10(3), 223-243.

Klacek, J., Vosvrda, M., \& Schlosser, S. (2007). KLE Production Function and Total Factor Productivity. Statistika: Statistics and Economy Journal, 44(4), 261-274.

Kumar, A., Birthal, P. S., \& Badruddin, A. (2004). Technical Efficiency in Shrimp Farming in India: Estimation and Implications. Indian Journal of Agricultural Economics, 59(3), 413-420. 
Kumbhakar, S. C., \& Lovell, C. A. K. (2000). Stochastic Frontier Analysis. Cambridge University Press, Cambridge, UK.

Lachaal, L., Chebil, A., \& Dhehibi, B. (2004). A Panel Data Approach to the Measurement of Technical Efficiency and its Determinants: Some Evidence from the Tunisian Agro-Food Industry. Agricultural Economics Review, 5(1), 15-23.

Lakner, S., \& Breustedt, G. (2015). Productivity and technical efficiency of organic farming - A literature survey. Acta fytotechn. Zootechn. 18 (special issue), Faculty of Agrobiology and Food Resources, Slovak University of Agriculture, Nitra, Slovakia.

Llorente, I., \& Luna, L. (2013). The Competitive Advantages Arising from Different Environmental Conditions in Seabream, Sparus aurata, Production in the Mediterranean Sea. Journal of the World Aquaculture Society, 44(5), 611-627.

Meeusen, W., \& Van der Broeck, J. (1977). Efficiency estimation from Cobb-Douglas production functions with composed error. International Economic Review, 18(2), 435-444.

Misra, J., \& Misra, S. R. (2014). Technical Efficiency of Fish Farms in West Bengal: Nature, Extent and Implications. Agricultural Economics Research Review, 27(2), 221-232.

Ngoc, P. T. A., Gaitán-Cremaschi, D., Meuwissen, M. P. M., Le, T. C., Bosma, R. H., Verreth, J., \& Lansink, A. O. (2018). Technical inefficiency of Vietnamese pangasius farming: A data envelopment analysis. Aquaculture Economics \& Management, 22(2), 229-243.

Pavelescu, F. (2011). Some aspects of the translog production function estimation. Romanian Journal of Economics, 32(1), 131-150.

Rezitis, A. N., \& Kalantzi, M. A. (2016). Investigating Technical Efficiency and Its Determinants by Data Envelopment Analysis: An Application in the Greek Food and Beverages Manufacturing Industry. Agribusiness, 32(2), 254-271.

Sharma, R., Leung, P., Chen, H., \& Peterson, A. (1999). Economic efficiency and optimum stocking densities in fish polyculture: An application of data envelopment analysis (DEA) to Chinese fish farms. Aquaculture, 180(3), 207-221.

Tingley, D., Pascoe, S., \& Coglan, L. (2005). Factors affecting technical efficiency in fisheries: stochastic production frontier versus data envelopment analysis approaches. Fisheries Research, 73(3), 363-376.

Tzouvlekas, V., Pantzios, C. J., \& Fotopoulos, C. (2001). Technical efficiency of alternative farming systems: the case of Greek organic and conventional olive-growing farms. Food Policy, 26(6), 549569. 
Table 1. European production of cultured sea bass and sea bream (2017)

\begin{tabular}{|l|c|c|c|c|c|c|}
\hline \multirow{2}{*}{ Country } & \multicolumn{2}{|c|}{ Sea bass } & \multicolumn{2}{c|}{ Sea bream } & \multicolumn{2}{c|}{ Total } \\
\cline { 2 - 7 } & $T n$ & $\%$ & $T n$ & $\%$ & $T n$ & $\%$ \\
\hline Croatia & 5,616 & 53.8 & 4,830 & 46.2 & $\mathbf{1 0 , 4 4 5}$ & $\mathbf{6 . 0}$ \\
\hline Cyprus & 2,254 & 31.3 & 4,950 & 68.7 & $\mathbf{7 , 2 0 4}$ & $\mathbf{4 . 1}$ \\
\hline France & 1,413 & 47.9 & 1,534 & 52.1 & $\mathbf{2 , 9 4 7}$ & $\mathbf{1 . 7}$ \\
\hline Greece & 44,285 & 44.2 & 55,948 & 55.8 & $\mathbf{1 0 0 , 2 3 2}$ & $\mathbf{5 7 . 6}$ \\
\hline Italy & 7,039 & 49,5 & 7,173 & 50.5 & $\mathbf{1 4 , 2 1 2}$ & $\mathbf{8 . 2}$ \\
\hline Malta & 59 & 2.4 & 2,458 & 97.6 & $\mathbf{2 , 5 1 8}$ & $\mathbf{1 . 4}$ \\
\hline Portugal & 701 & 40.3 & 1,038 & 59.7 & $\mathbf{1 , 7 3 9}$ & $\mathbf{1 . 0}$ \\
\hline Slovenia & 80 & 100.0 & 0 & 0.0 & $\mathbf{8 0}$ & $\mathbf{0 . 0}$ \\
\hline Spain & 17,656 & 50.9 & 17,005 & 49.1 & $\mathbf{3 4 , 6 6 1}$ & $\mathbf{1 9 . 9}$ \\
\hline \multicolumn{1}{|c|}{ Total } & $\mathbf{7 9 , 1 0 2}$ & $\mathbf{4 5 . 5}$ & $\mathbf{9 4 , 9 3 6}$ & $\mathbf{5 4 . 5}$ & $\mathbf{1 7 4 , 0 3 8}$ & $\mathbf{1 0 0 . 0}$ \\
\hline
\end{tabular}

Source: EUMOFA using EUROSTAT data. 
Table 2. Sample descriptive statistics (period 2008-2017)

\begin{tabular}{|c|c|c|c|c|c|}
\hline Variable & $N$ & Mean & $S D$ & Min. & Max. \\
\hline$Y=$ Cultured sea bass and sea bream production (tons) & 591 & 3,776 & 8,430 & 2 & 58,931 \\
\hline$L A B=$ Labor (number of employees) & 591 & 77 & 175 & 1 & 1,150 \\
\hline CAP $=$ Capital (total assets, mill. USD) & 591 & 34.6 & 82.8 & 0.3 & 692.0 \\
\hline$Y E A R=$ Time trend $($ year $)$ & 591 & $2,012.49$ & 2.64 & 2,008 & 2,017 \\
\hline WEST $=$ Firms located in the West Mediterranean Sea (dummy) & 591 & 0.26 & 0.44 & 0 & 1 \\
\hline EAST = Firms located in the East Mediterranean Sea (dummy) & 591 & 0.42 & 0.49 & 0 & 1 \\
\hline ORG $=$ Production type (dummy) & 591 & 0.29 & 0.45 & 0 & 1 \\
\hline$A G E=$ Firm's experience (years) & 591 & 16.71 & 7.72 & 0 & 41 \\
\hline SIZE $=$ Firm's size (inverse of annual revenues, $1 /$ mill. USD) & 591 & 0.78 & 4.16 & 0 & 83.33 \\
\hline
\end{tabular}

Source: authors' elaboration using EUMOFA and ORBIS databases. 
Table 3. Maximum Likelihood estimates of the SPF and inefficiency effects models for cultured sea bass and sea bream in the Mediterranean Sea

\begin{tabular}{|c|c|c|c|c|c|}
\hline \multirow[t]{2}{*}{ Variable } & \multirow[t]{2}{*}{ Parameter } & \multicolumn{2}{|c|}{$\begin{array}{c}\text { Cobb-Douglas } \\
\text { production function }\end{array}$} & \multicolumn{2}{|c|}{$\begin{array}{c}\text { Translog } \\
\text { production function }\end{array}$} \\
\hline & & Coefficient & t-ratio & Coefficient & t-ratio \\
\hline \multicolumn{6}{|l|}{ Stochastic frontier model } \\
\hline Constant & $\beta_{0}$ & 6.5436 & 0.30 & 22.1466 & 1.08 \\
\hline$Y E A R$ & $\beta_{1}$ & -0.0030 & 0.28 & -0.0096 & 0.92 \\
\hline $\operatorname{Ln}(L A B)$ & $\beta_{2}$ & $0.3032^{* * *}$ & 5.94 & $1.4366^{* * *}$ & 5.65 \\
\hline $\operatorname{Ln}(C A P)$ & $\beta_{3}$ & $0.6587^{* * *}$ & 13.94 & -0.2642 & 0.76 \\
\hline $\operatorname{Ln}(L A B)^{2}$ & $\beta_{4}$ & & & $0.0542^{* * *}$ & 3.01 \\
\hline $\operatorname{Ln}(C A P)^{2}$ & $\beta_{5}$ & & & $0.0803^{* * *}$ & 3.29 \\
\hline $\operatorname{Ln}(L A B) \times \operatorname{Ln}(C A P)$ & $\beta_{6}$ & & & $-0.1612^{* * *}$ & 4.59 \\
\hline \multicolumn{6}{|l|}{ Inefficiency effects model } \\
\hline Constant & $\delta_{0}$ & -63.1363 & 0.70 & -18.8925 & 0.21 \\
\hline$Y E A R$ & $\delta_{1}$ & 0.0319 & 0.71 & 0.0099 & 0.23 \\
\hline WEST & $\delta_{2}$ & $-1.1670^{* * *}$ & 3.28 & $-1.0588^{* * *}$ & 3.04 \\
\hline EAST & $\delta_{3}$ & $-1.4409^{* *}$ & 2.21 & $-1.6055^{* *}$ & 2.27 \\
\hline$O R G$ & $\delta_{4}$ & -0.0702 & 0.26 & -0.1894 & 0.64 \\
\hline$A G E$ & $\delta_{5}$ & -0.0292 & 1.40 & -0.0321 & 1.47 \\
\hline SIZE & $\delta_{6}$ & $0.1059^{* * *}$ & 5.44 & $0.1046^{* * *}$ & 5.71 \\
\hline \multicolumn{6}{|l|}{ Variance parameters } \\
\hline $\operatorname{Sigma} u$ & $\sigma_{u}^{2}$ & $0.8212^{* * *}$ & 4.47 & $0.8526^{* * *}$ & 4.50 \\
\hline $\operatorname{Sigma} v$ & $\sigma_{v}^{2}$ & $0.2209^{* * *}$ & 11.27 & $0.1851^{* * *}$ & 10.46 \\
\hline Lambda & $\lambda$ & $3.7169^{* * *}$ & 19.83 & $4.6050^{* * * *}$ & 24.29 \\
\hline Log-likelihood & & -397.47 & & -378.06 & \\
\hline Likelihood ratio test (Wald chi-square) & & $1,599.92^{* * * *}$ & & $4,275.35^{* * *}$ & \\
\hline Number of observations & & 591 & & 591 & \\
\hline Number of firms & & 73 & & 73 & \\
\hline LR test: all $\beta_{\mathrm{j}, \mathrm{k}}=0$ & & $38.82^{* * *}$ & & & \\
\hline
\end{tabular}

Notes: The Battese and Coelli's $(1993,1995)$ model has been used to estimate both production functions. $t$-ratios based on cluster-robust standard errors. $\lambda=\sigma_{u}{ }^{2} / \sigma_{v}^{2}$. LR $=$ Likelihood-ratio test.

${ }^{* * *}$ Significance at the $1 \%$ level. ${ }^{* *}$ Significance at the $5 \%$ level. ${ }^{*}$ Significance at the $10 \%$ level. 
Table 4. Distribution of firms' average estimates of TE values in decile range

\begin{tabular}{|c|c|c|c|}
\hline TE value & Frequency & \% & Cumulative \% \\
\hline Below 0.60 & 1 & 1.4 & 1.4 \\
\hline $0.60-0.70$ & 3 & 4.1 & 5.5 \\
\hline $0.70-0.80$ & 4 & 5.5 & 11.0 \\
\hline $0.80-0.90$ & 20 & 27.4 & 38.4 \\
\hline Over 0.90 & 45 & 61.6 & 100.0 \\
\hline Total & $\mathbf{7 3}$ & $\mathbf{1 0 0 . 0}$ & - \\
\hline
\end{tabular}

Note: TE values obtained with the translog production function. 
Table 5. Distribution of firms' average estimates of TE values by country

\begin{tabular}{|l|c|c|c|c|c|}
\hline \multirow{2}{*}{ Country } & Number & \multicolumn{4}{|c|}{ TE distribution by country } \\
\cline { 3 - 6 } & of firms & Mean & Min. & Max. & Range \\
\hline Croatia & 7 & 0.820 & 0.670 & 0.946 & 0.276 \\
\hline Cyprus & 3 & 0.991 & 0.964 & 1.026 & 0.063 \\
\hline France & 3 & 0.888 & 0.864 & 0.922 & 0.058 \\
\hline Greece & 27 & 0.936 & 0.750 & 1.004 & 0.254 \\
\hline Italy & 15 & 0.843 & 0.594 & 0.988 & 0.394 \\
\hline Slovenia & 2 & 0.830 & 0.750 & 0.910 & 0.160 \\
\hline Spain & 16 & 0.929 & 0.812 & 1.00 & 0.191 \\
\hline All countries & $\mathbf{7 3}$ & $\mathbf{0 . 8 9 1}$ & $\mathbf{0 . 5 9 4}$ & $\mathbf{1 . 0 2 6}$ & $\mathbf{0 . 4 3 2}$ \\
\hline
\end{tabular}

Note: TE values obtained with the translog production function. 


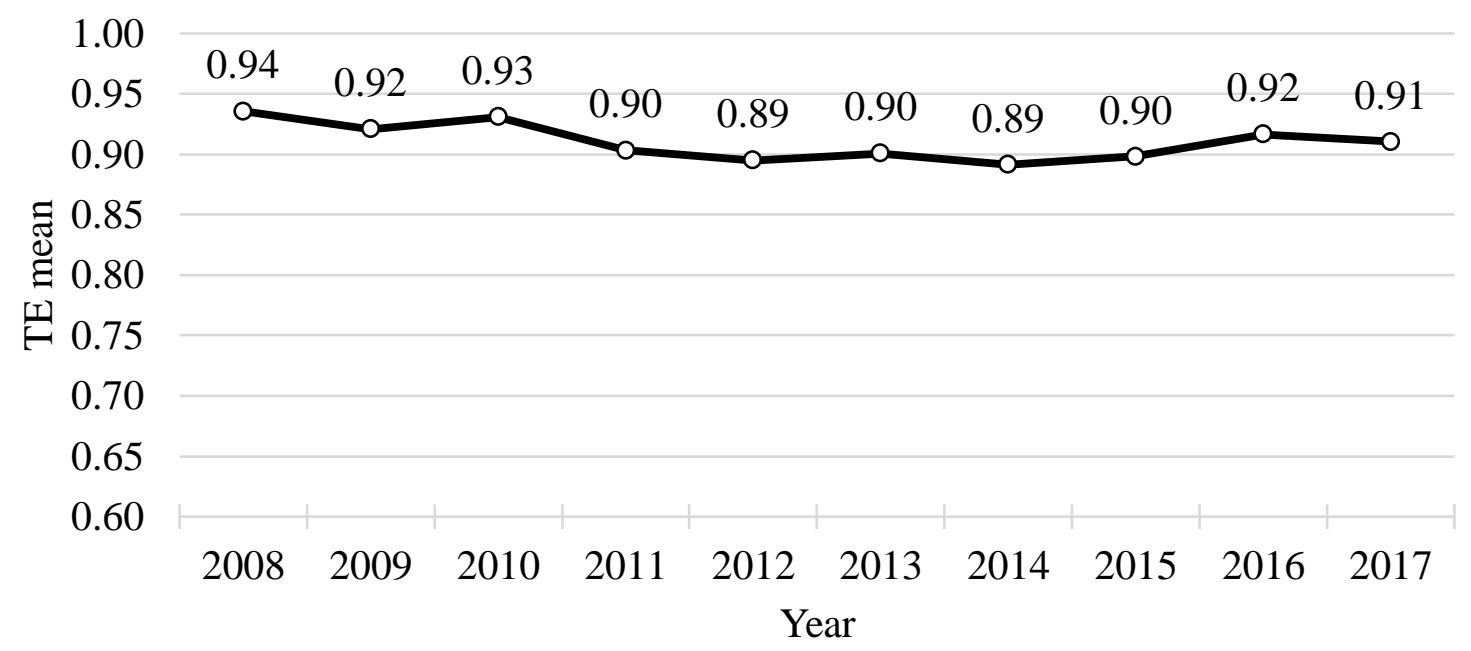

Figure 1. Annual evolution of firms' average estimates of TE values Note: TE values obtained with the translog production function. 